\title{
A DLC/diamond bilayer approach for reducing the initial friction towards a high bearing capacity
}

\author{
M. Amaral ${ }^{\mathrm{a}, \mathrm{b}, *}$, D.J. Carreira ${ }^{\mathrm{a}}$, A.J.S. Fernandes ${ }^{\mathrm{b}}$, C.S. Abreu ${ }^{\text {c,d }}$, F.J. Oliveira ${ }^{\mathrm{a}}$, J.R. Gomes ${ }^{\mathrm{d}}$, R.F. Silva ${ }^{\mathrm{a}}$ \\ ${ }^{a}$ CICECO, Department Ceramics Glass Engineering, University of Aveiro, 3810-193 Aveiro, Portugal \\ ${ }^{\mathrm{b}}$ I3N, Physics Department, University of Aveiro, 3810-193 Aveiro, Portugal \\ c Physics Department, Porto Superior Engineering Institute (ISEP), Portugal \\ ${ }^{\mathrm{d}}$ Centre for Mechanical and Materials Technologies (CT2M), University of Minho, Portugal
}

\section{A R T I C L E I N F O}

\section{Article history:}

Received 22 September 2011

Received in revised form

25 May 2012

Accepted 30 May 2012

Available online 7 June 2012

\section{Keywords:}

DLC

CVD diamond

Tribology

Contact mechanics

\begin{abstract}
A B S T R A C T
Sliding contact mechanics is used to account for the net increase of the bearing capacity of high wearresistant CVD diamond coatings when an outer layer of a DLC lubricant film is deposited on their top surface. Experimental results, namely the critical failure load, taken from reciprocating ball-on-plate tribological testing of such DLC/diamond bilayers, are on the basis of this statement. DC magnetron sputtering was used to grow thin DLC lubricant coatings (non-hydrogenated and hydrogenated varieties) on the top of CVD diamond films (microcrystalline and nanocrystalline types). The application of the von Mises maximum yield parameter $\left(\sqrt{J_{2}}\right)$ criterion demonstrates to be an adequate method for designing low-friction and high-bearing capacity systems for high-demanding tribological applications. Calculation of $\sqrt{J_{2}}$ supports that the most significant increase observed on the coatings' bearing capacity (from $20 \mathrm{~N}$ to $60 \mathrm{~N}$ ) takes place when microcrystalline diamond is coated by hydrogenated DLC that decreases the initial friction coefficient peak (from 0.76 to 0.41 ).
\end{abstract}

(c) 2012 Elsevier B.V. All rights reserved.

\section{Introduction}

Chemical vapor deposition (CVD) diamond is known for its outstanding physical and chemical properties such as an extreme hardness, high wear resistance and chemical inertness, being usually used for high demanding tribological applications. The CVD diamond films are composed by grains with dimensions within $1-10 \mu \mathrm{m}$ or $10-100 \mathrm{~nm}$ ranges, corresponding to the socalled microcrystalline diamond (MCD) and nanocrystalline diamond (NCD) varieties, respectively. Grain size strongly influences the CVD diamond surface roughness which in turn determines the tribological behavior of the coatings. In self-mated contacts, this gives rise to high initial friction $\left(\mu_{\max }\right)$ levels, which is especially true for the MCD morphology $\left(0.35 \leq \mu_{\max } \leq 0.65[1,2]\right)$. In this case, surface asperities have to fracture or to overcome each other during sliding, expending a large amount of mechanical energy, thus causing such high initial values of friction. After that, extremely low friction coefficient values are achieved in the steady-state regime $\left(0.02 \leq \mu_{\mathrm{st}} \leq 0.05[1,2]\right)$ as well as a very low wear rate $\left(10^{-8} \mathrm{~mm}^{3} \mathrm{~N}^{-1} \mathrm{~m}^{-1} \leq k \leq 10^{-7} \mathrm{~mm}^{3} \mathrm{~N}^{-1} \mathrm{~m}^{-1}\right.$ $[1,2])$, exhibiting excellent endurance.

\footnotetext{
* Corresponding author at: University of Aveiro CICECO, Department. Ceramics Glass Engineering, 3810-193 Aveiro, Portugal. Fax: +35 1234370204.

E-mail address: margarida.amaral@ua.pt (M. Amaral).
}

Diamond-like carbon (DLC) films are amorphous carbon coatings presenting a mixture of $\mathrm{sp}^{2}$ and $\mathrm{sp}^{3}$ hybridizations. In fact, there are different forms of DLC whose structure, properties and tribological behavior depend on their $\mathrm{sp}^{2}$ and $\mathrm{sp}^{3}$-bond character as well as of hydrogen content [3]. Generally, due to its low shear strength, when applied on a sliding surface, the DLC coatings can lower friction and wear and for that reason are considered as solid lubricants [4]. However, in abrasive conditions, DLC coatings do not have enough endurance [5].

The combination of DLC and CVD diamond in a bilayer coating gathers the best properties of the two films individually. This approach was reported by some authors [5-8] having different purposes. Csorbai et al. [6] prepared a pinhole-free thin DLCdiamond double layer for corrosion protection and assessed the effect of deposition parameters on the protective properties of the layers. Hanyu et al. [5] combined DLC with a CVD smooth surface diamond coating in order to improve the cutting performance of tools for the machining of aluminum alloys. The bilayer lead to a better anti-sticking property of cutting tools and successfully increased the tool endurance. Miyoshi $[7,8]$ focused its study on tribological applications in ultrahigh vacuum, where CVD diamond presents a high coefficient of friction and low wear resistance. The deposition of a thin film of amorphous carbon on CVD diamond in one of the sliding parts decreased the coefficient of friction and the wear rate, proving to be an effective wear-resistant film, lubricating the diamond coating in ultrahigh 
vacuum [7]. In a previous work by the same author, tribological tests performed in dry nitrogen and in humid air revealed a low steady-state coefficient of friction and low wear rate, showing that the bilayer presents an excellent tribological behavior regardless of the environment [8].

The work hereby presented attempts to understand why an external solid lubricant DLC layer helps on increasing the total load that a CVD diamond coating can withstand before failure (load bearing capacity). The effect of dynamic friction is to add a compressive stress to the front edge of the moving contact and to intensify the tensile stress at the back edge [9]. As a result, yielding occurs at lower loads for the coatings presenting higher initial friction levels [9]. In the present work, the tribological performance of the DLC-diamond bilayers is tested using the selfmated reciprocating ball-on-plate configuration. Thin DLC films, with and without hydrogen, were deposited on the top of both the MCD and NCD coating varieties. DC magnetron sputtering was the chosen technique for DLC deposition due to versatility and ability to produce hydrogenated coatings by reactive sputtering [3]. Works reporting a similar combination of DLC and diamond layers used pulsed laser deposition [6], rf plasma CVD [5] and ion beam $[7,8]$ techniques.

\section{Experimental}

CVD diamond films were deposited on silicon nitride $\left(\mathrm{Si}_{3} \mathrm{~N}_{4}\right)$ ceramic plates and balls. Plates of $10 \mathrm{~mm}$ of diameter and $3 \mathrm{~mm}$ of thickness were homemade using a preparation routine described elsewhere [10], while $\mathrm{Si}_{3} \mathrm{~N}_{4}$ commercial balls of $5 \mathrm{~mm}$ of diameter (Cerbec ${ }^{\mathbb{R}}$, CoorsTek) act as counter bodies in the sliding experiments. The $\mathrm{Si}_{3} \mathrm{~N}_{4}$ plates were ground and polished with $15 \mu \mathrm{m}$ diamond slurry, ultrasonic cleaned and then seeded, together with the balls, for $1 \mathrm{~h}$ in an ultrasonic suspension using 0.5-1 $\mu \mathrm{m}$ sized diamond powder in ethanol, followed by cleaning with ethanol for $5 \mathrm{~min}$. After surface pre-treatment, two varieties of CVD diamond were grown by hot-filament CVD technique: microcrystalline (MCD) and nanocrystalline (NCD) films. The deposition parameters used are listed in Table 1.

Diamond-like-carbon (DLC) layers were deposited by PVD on the diamond coated plates and balls, using a DC magnetron sputtering system. The target was a 2 -in. diameter pure graphite plate with $3 \mathrm{~mm}$ of thickness, located at $10 \mathrm{~cm}$ from the substrate holder. A residual pressure near $1 \times 10^{-5} \mathrm{mbar}$ was attained before deposition. The gas used was argon to produce nonhydrogenated carbon films (DLC) and a mixture of argon and methane to produce hydrogenated carbon films (DLC-H), Table 1. The target was pre-sputtered for about 10 min before deposition, to remove any surface impurities, with the substrates temporarily protected by a shield. Silicon (Si) wafers were also coated with DLC and DLC-H, in order to assess film thickness by ellipsometry measurements (Jobin Yvon AutoSE ellipsometer, $70^{\circ}$ incidence angle, $440-850 \mathrm{~nm}$ ). The use of $\mathrm{Si}$ as a substrate makes easier the experimental curve fitting procedure required to estimate the coating thickness by this technique.

All the coated substrates were characterized by atomic force microscopy (AFM, Digital Instruments Nanoscope IIIa), fieldemission scanning electron microscopy (Hitachi SU-70 FE-SEM) and $\mu$-Raman spectrometry (Horiba Jobin Yvon HR800 at $325 \mathrm{~nm}$ ). The tribological characterization of the DLC/diamond bilayers was achieved using a ball-on-flat reciprocating tribometer (PLINT TE67/R). Unlubricated self-mated tests were performed in ambient atmosphere ( $\mathrm{RH}$ of $50-60 \%$ ) at room temperature, with constant stroke $(8 \mathrm{~mm})$ and frequency $(1 \mathrm{~Hz})$. The duration of the tribological test was $2 \mathrm{~h}$, which corresponded to a sliding distance of approximately $115 \mathrm{~m}$. The normal applied load varied in the range $5-80 \mathrm{~N}$ (at intervals of $10 \mathrm{~N}$, for loads $>10 \mathrm{~N}$ ) applied directly over the ball specimens. For all samples, the critical load was determined by performing tests with successively higher loads until failure occurs. The friction force was measured by a load cell. Afterwards, all the samples were observed by SEM, AFM and $\mu$-Raman spectroscopy. The wear coefficient of the balls was assessed by measuring the corresponding wear scar diameter in SEM [1], while AFM bearing function enabled volume loss quantification of plate wear tracks [11].

\section{Results and discussion}

\subsection{Characterization of the diamond monolayers and the DLC/ diamond bilayers}

SEM top-view micrographs of the coatings studied in the present work are shown in Fig.1. As it can be seen, the microsized grains $(0.5-2 \mu \mathrm{m})$ of the diamond film (Fig.1a) are still visible after coating with DLC and DLC-H (Fig.1b and c). The main morphological difference between DLC/MCD bilayers and the MCD monolayer is the smoothening of the diamond grain edges by coating with the amorphous carbon film, as depicted in the insets of Fig.1a-c. Samples coated with NCD present the distinctive nano-sized grain morphology even after being coated with amorphous carbon films, Fig.1d-f. AFM scans performed in tapping mode assessed the surface roughness (RMS) of the unworn coatings (Fig. 2). No significant differences were found on samples before and after coating with DLC films confirming the results from SEM characterization. It is also clear, from these AFM data, that NCD coatings are much smoother than the MCD ones.

Cross-section views by SEM (an example is shown in Fig. 3) allowed the measurement of diamond film thicknesses of about $6 \mu \mathrm{m}$ for MCD and $3 \mu \mathrm{m}$ for NCD layers. DLC thicknesses estimated by ellipsometry measurements were found to be approximately $540 \mathrm{~nm}$ and $350 \mathrm{~nm}$ for DLC and DLC-H, respectively. The growth rate of DLC-H is lower than DLC because the deposition of hydrogenated amorphous carbon films is a reactive process that requires the addition of a hydrocarbon gas source, which reduces

Table 1

Conditions of deposition of diamond and DLC films.

\begin{tabular}{|c|c|c|c|c|c|c|c|}
\hline HFCVD & $\mathrm{CH}_{4} / \mathrm{H}_{2}$ & $\mathrm{Ar} / \mathrm{H}_{2}$ & $\begin{array}{l}\text { Gas flow } \\
\left(\mathrm{ml} \mathrm{min}{ }^{-1}\right)\end{array}$ & Pressure (mbar) & $\begin{array}{l}\text { Filament } \\
\text { temperature }\left({ }^{\circ} \mathrm{C}\right)\end{array}$ & $\begin{array}{l}\text { Substrate } \\
\text { temperature }\left({ }^{\circ} \mathrm{C}\right)\end{array}$ & $\begin{array}{l}\text { Deposition time } \\
\text { (h) }\end{array}$ \\
\hline MCD & 0.02 & - & 100 & 175 & 2300 & 800 & 6 \\
\hline NCD & 0.04 & 0.1 & 200 & 100 & 2250 & 700 & 10 \\
\hline PVD & $\operatorname{Ar}(\mathrm{sccm})$ & $\mathrm{CH}_{4}(\mathrm{sccm})$ & Power (w) & Pressure (mbar) & $\begin{array}{l}\text { Distance Target/ } \\
\text { samples }(\mathrm{cm})\end{array}$ & $\begin{array}{l}\text { Substrate } \\
\text { temperature }\left({ }^{\circ} \mathrm{C}\right)\end{array}$ & $\begin{array}{l}\text { Deposition time } \\
\text { (h) }\end{array}$ \\
\hline DLC & 10 & - & 110 & $1.9 \times 10^{-3}$ & 10 & 100 & 4 \\
\hline DLC-H & 9.3 & 0.7 & 110 & $1.9 \times 10^{-3}$ & 10 & 100 & 4 \\
\hline
\end{tabular}



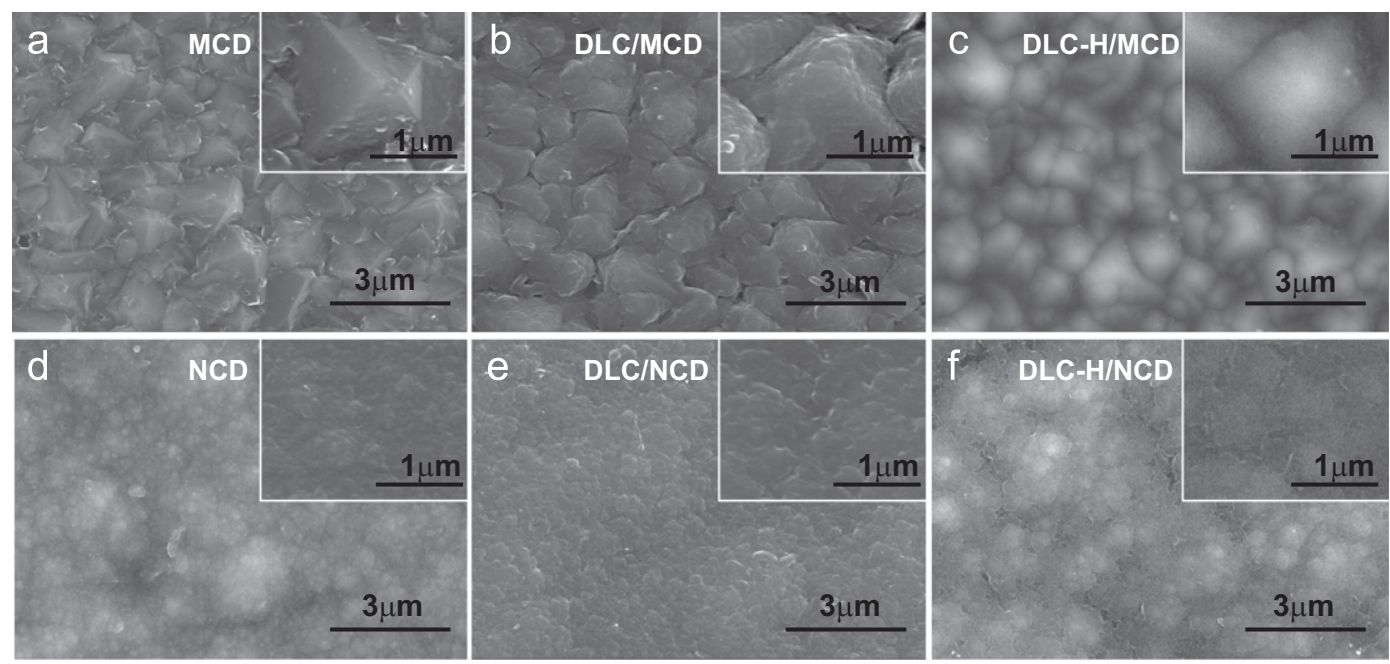

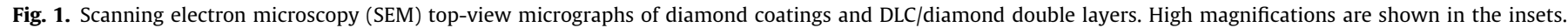

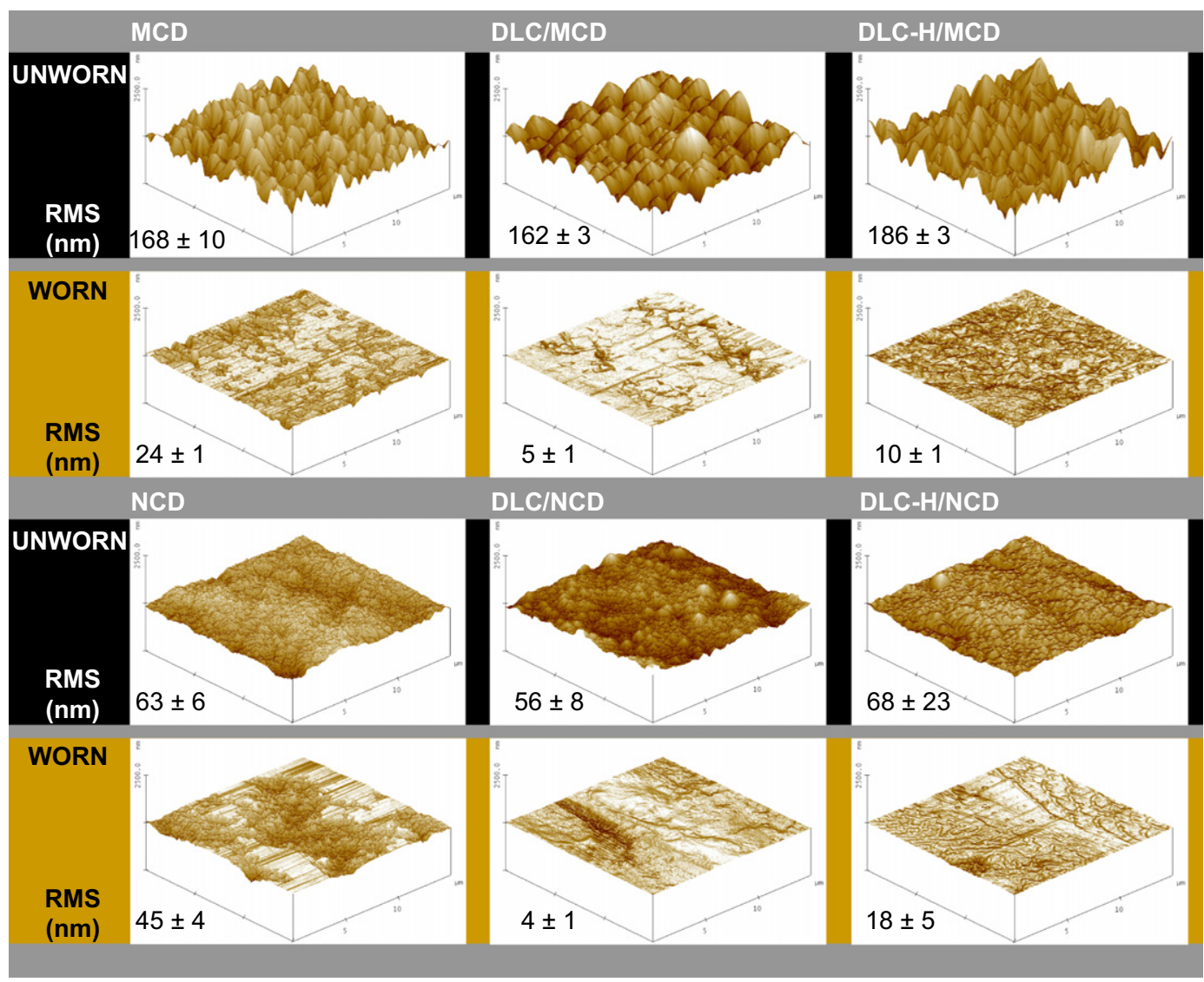

Fig. 2. Atomic force microscopy (AFM) scans of unworn and worn coatings and respective surface roughness values (RMS).

the partial argon pressure and decreases the sputtering rate of the carbon target [12]. Nonetheless, both amorphous carbon films are thin when compared to the diamond ones (6-18\% of diamond thickness values) and for that reason unable to induce large morphological differences on diamond surface, as was shown by SEM and AFM analysis.

Raman spectra revealed the MCD and NCD signatures for the samples coated only with diamond, Fig. $4 a$ and b. For the MCD layer, the main diamond peak $\left(1331 \mathrm{~cm}^{-1}\right)$ is visible as well as the D and $G$ graphitic bands ( $1365 \mathrm{~cm}^{-1}$ and $1565 \mathrm{~cm}^{-1}$, respectively). For NCD, the $\mathrm{D}$ and the $\mathrm{G}$ bands are wider and more intense than the diamond peak and there is an evidence of a new peak at $1170 \mathrm{~cm}^{-1}(\mathrm{C}-\mathrm{H}$ chains). After coating with DLC and DLC-H, those signatures are no longer detectable and a typical amorphous carbon spectrum arises instead. This is expected to happen as the $325 \mathrm{~nm}$ laser penetration depth is about 10-15 nm [13], lower than DLC thickness. Both DLC coatings present two bands: D and $\mathrm{G}$. The $\mathrm{D}$ band appears at $1365 \mathrm{~cm}^{-1}$ and the $G$ band is located at $1575 \mathrm{~cm}^{-1}$ for the nonhydrogenated film and at $1582 \mathrm{~cm}^{-1}$ for the hydrogenated one. The shift of the $G$ band towards $1575 \mathrm{~cm}^{-1}$ indicates a slightly change on 
carbon-bonding configuration of the film caused by hydrogen incorporation [14].

\subsection{Friction coefficient and wear}

The friction curves shown in Fig. 5 for the different tested samples were obtained under the maximum testing load that the films could withstand without failure ( $W_{c}$, critical load). All the curves are characterized by an initial friction peak $\left(\mu_{\max }\right)$, a running-in step that lasts for a short distance $(<10 \mathrm{~m})$ in most of the cases, and a stage where the coefficient of friction levels off and tends to stabilise in low steady-state values $\left(\mu_{\mathrm{st}}\right)$. The complete set of friction coefficient values is given in Fig. 6. The samples coated with MCD present higher initial friction peaks than the ones coated with NCD. This behaviour is related to the mechanical interlocking between asperities taking place during the relative motion of contacting surfaces [1], which is more operative in the case of MCD due to its higher nominal surface roughness (RMS), Fig. 2.

The DLC deposition on top of the diamond layer decreases the $\mu_{\text {max }}$ values, mainly in the case of the MCD coatings, Fig. 6 . This lubricant effect is preeminent for the combination DLC-H/MCD, reducing in $46 \%$ the value of $\mu_{\max }$ but, above all, increasing the critical load $\left(W_{c}\right)$ from 20 to $60 \mathrm{~N}$, Fig. 5. The $\mu_{\max }$ decrease observed for the DLC-H/MCD coated material is not the result of the higher applied load (60 N) since tests performed at $20 \mathrm{~N}$ also showed a lower value $\left(\mu_{\max }=0.50\right)$ than the one found for MCD $\left(\mu_{\max }=0.76\right)$. Instead, the structure and chemical bonds of DLC-H films are proposed as accountable for this behaviour. Several authors [15-18] reported that hydrogen on the DLC film surface is

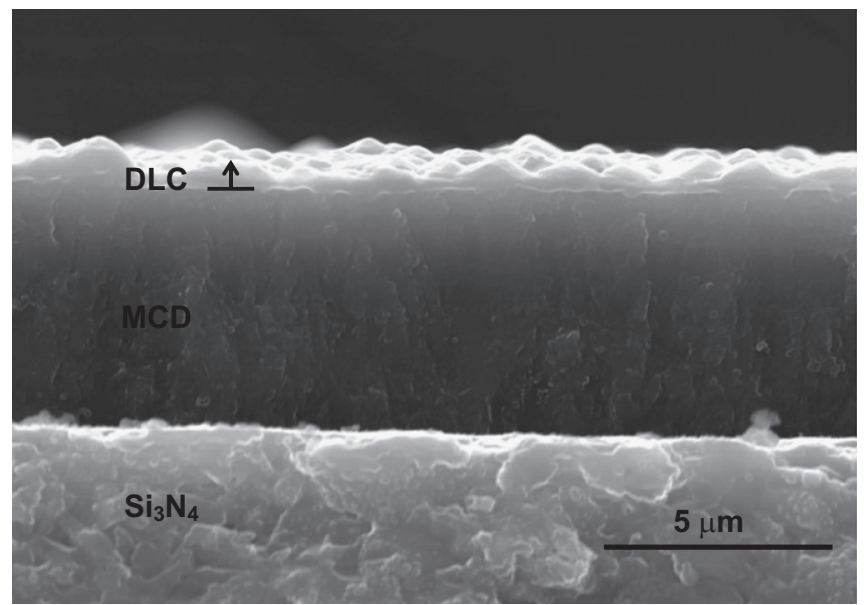

Fig. 3. Scanning electron microscopy (SEM) cross-section image of DLC/MCD bilayer coating on silicon nitride $\left(\mathrm{Si}_{3} \mathrm{~N}_{4}\right)$ substrate.

a

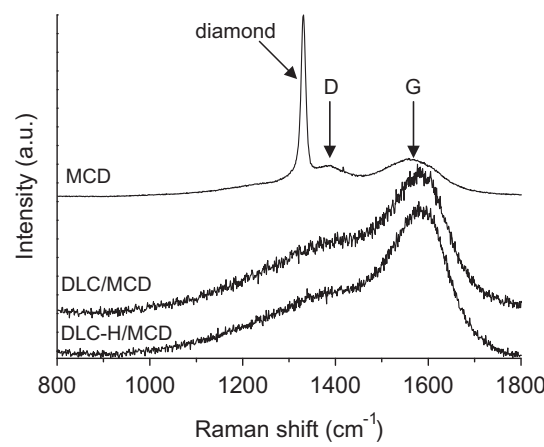

responsible for a large decrease in the unsaturated carbon bonds at the interface when compared to non-hydrogenated films. Passivation of dangling bonds by the linking of $\mathrm{H}$ to $\mathrm{C}$ atoms reduces the attractive forces between the two surfaces in sliding contact and reduces friction [18]. Molecular dynamic simulations have supported the passivation hypothesis as an explanation for the low DLC-H friction $[15,18]$.

Among the set of tested samples, DLC/NCD is the coating that presents worse frictional behavior. It has the longest running-in period and the highest steady-state friction coefficient, Figs. 5e and 6. SEM images of the wear track produced at the test load of $5 \mathrm{~N}$, Fig. 7, reveal partial delamination of the film. This set of facts is an outcome of the contact between ultra smooth surfaces (RMS $=4 \pm 1 \mathrm{~nm}$, Fig. 2) and strong adhesion forces established among them, resulting from linkages with dangling bonds on the counterpart surface.

The wear coefficient values $(K)$ depicted in Fig. 8 were assessed for plates and balls in accordance with Archard's law: $K=V / x W$, were $V$ is the volumetric wear, $x$ is the sliding distance, and $W$ is the applied load. The coated plates present higher wear coefficients than the balls. This difference was expected and is a result of fatigue wear mechanism characteristic of intermittent loading on the flat specimen.

The NCD single layer exhibits the lowest assessed wear rate, with extremely low values $\left(3 \times 10^{-8} \mathrm{~mm}^{3} \mathrm{~N}^{-1} \mathrm{~m}^{-1}\right)$, given that is one of the smoothest films and harder than DLC. As expected, the sample presenting the highest wear rate $\left(5.2 \times 10^{-7} \mathrm{~mm}^{3} \mathrm{~N}^{-1} \mathrm{~m}^{-1}\right)$ is the one which has the worst frictional behavior above described, the DLC/NCD bilayer.

In general, double layer coatings presented higher wear rates than the single ones, which does not surprises considering that the diamond film is covered with the amorphous carbon that is less hard, decreasing the hardness of the top ultimate layer, thus becoming more wear susceptible. Analysis of the wear track of DLC-H/MCD and DLC-H/NCD by Raman spectroscopy, Fig. 9, showed only MCD and NCD characteristic features attesting the removal of the softer layer during sliding. Nevertheless, the wear coefficient values assessed for double coatings are in the range of mild wear regime $\left(10^{-7} \mathrm{~mm}^{3} \mathrm{~N}^{-1} \mathrm{~m}^{-1}\right)$.

Among the tested DLC coatings, hydrogenated amorphous carbon films are the ones presenting the lowest wear rates. In fact, in the literature, those films are described as being more wear resistant due to features such as self-healing ability, strain tolerance and compressibility which make them ideal solid lubricants [16].

\subsection{Importance of the reduction of the running-in friction on the bearing capacity}

In the present work there is one result that outstands: the reduction of the friction coefficient and the increase of the critical

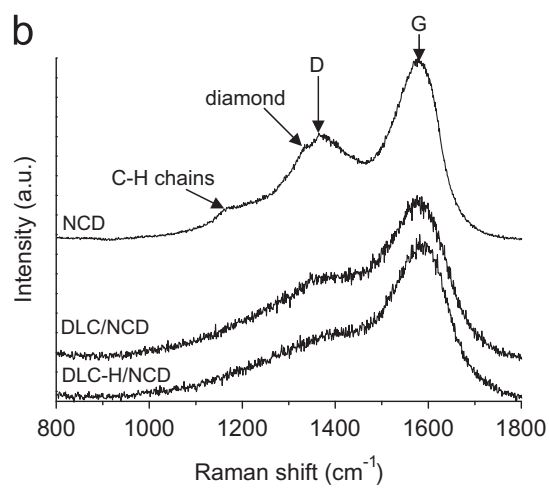

Fig. 4. UV micro-Raman spectra of as-deposited diamond coatings and DLC/diamond double layers: (a) MCD and (b) NCD as first layers, respectively. 

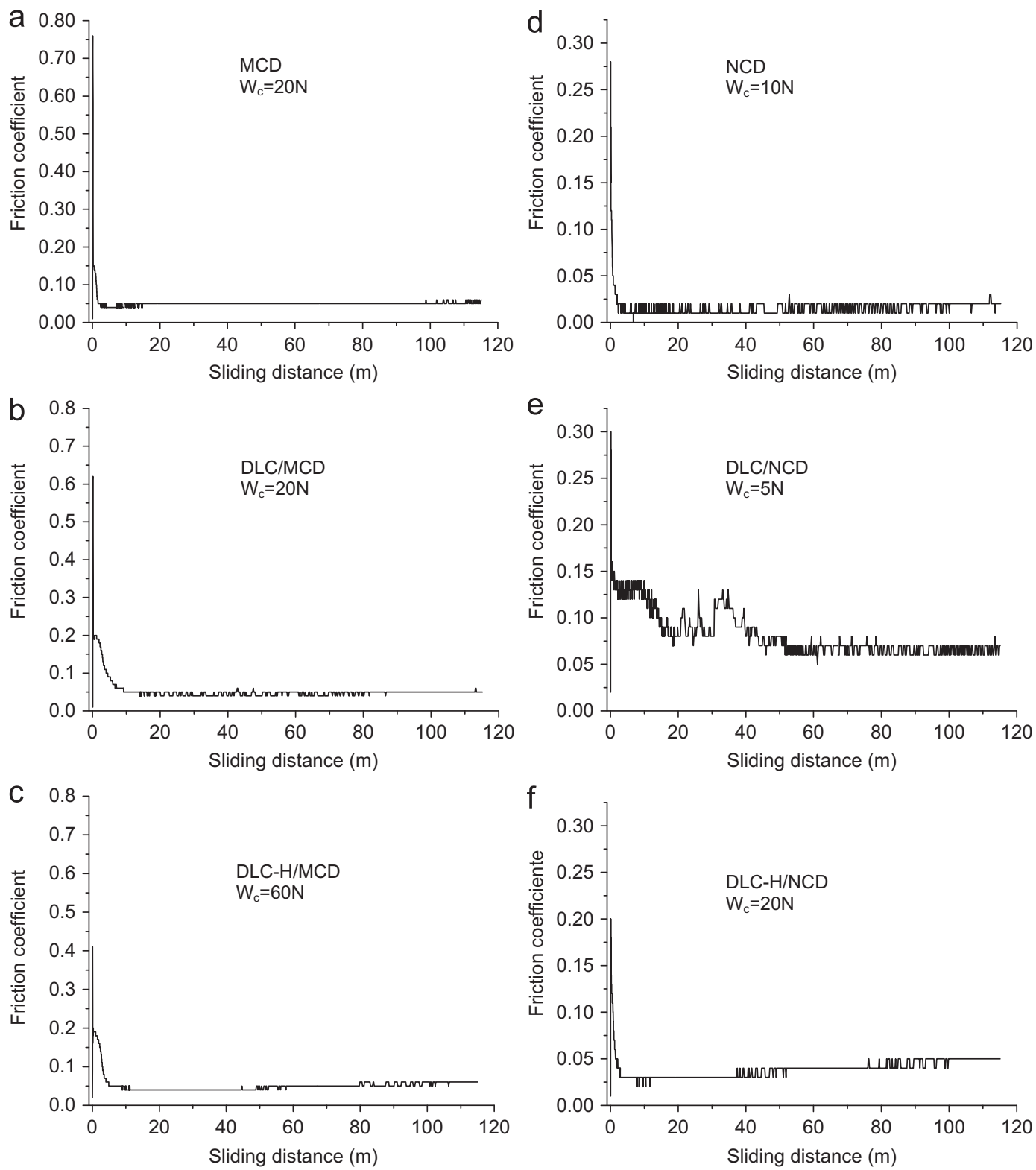

Fig. 5. Friction curve evolution as a function of sliding distance under critical load, for diamond coatings and DLC/diamond double layers.

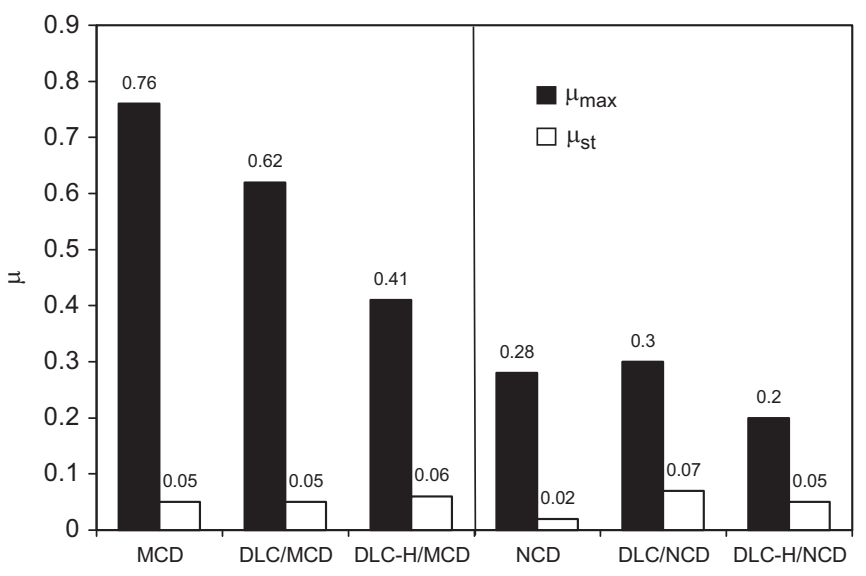

Fig. 6. Coefficient of friction of the homologous pairs under critical load: initial $\left(\mu_{\max }\right)$ and steady-state $\left(\mu_{\mathrm{st}}\right)$ values. load when a thin coating of DLC-H is deposited on top of a MCD film. In this subsection, explanations based on contact mechanics will be discussed.

A first, simple, calculation demonstrates why the amorphous carbon films decrease the friction coefficient relatively to the uncoated MCD. This is related to the intrinsic elastic properties of the coatings, namely Young's modulus and Poisson's ratio and their effect in the maximum shear stress values $\left(\tau_{1}\right)$. Fig. 10 presents the $\tau_{1}$ values resulting from the normal Hertzian contact of a spherical indenter on a flat surface, plotted as a function of $z$ (distance to the surface). Calculation of $\tau_{1}$ is made accordingly to the following equations [19]:

$a=\left(3 W R / 4 E^{*}\right)^{1 / 3}$

$p_{0}=\left(6 W E^{* 2} / R^{2} \pi^{3}\right)^{1 / 3}$

$\sigma_{x x}=\sigma_{y y}=-p_{0}\left[(1+v)(1-z / a \arctan (a / z))-0.5\left(1+z^{2} / a^{2}\right)^{-1}\right]$ 


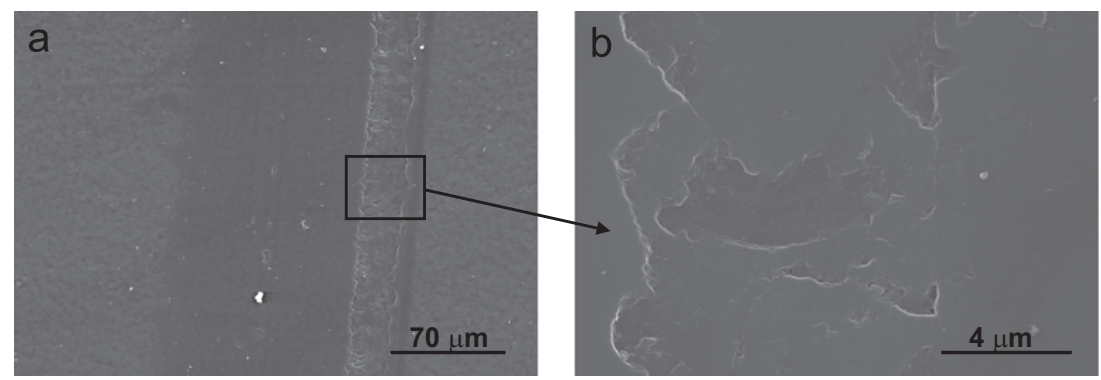

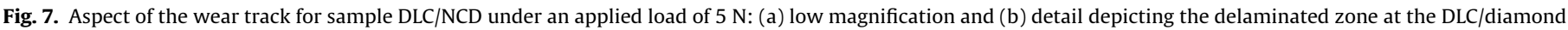
interface.

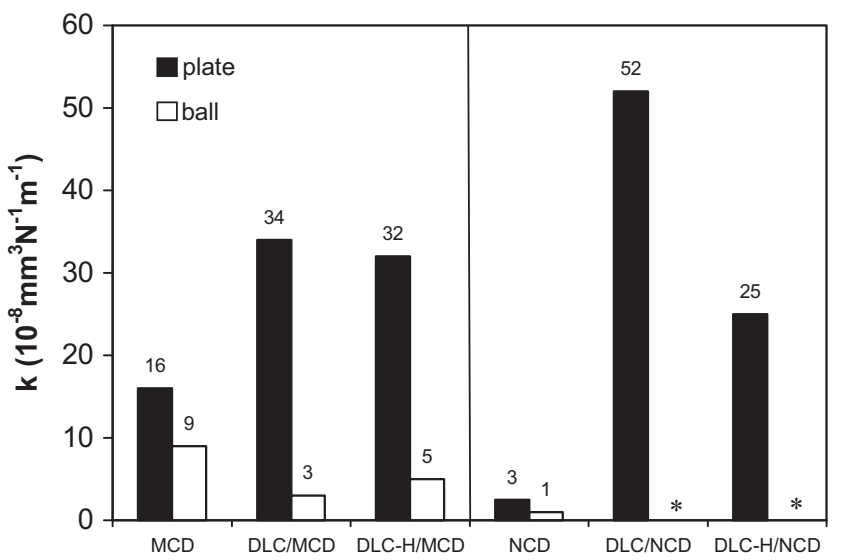

Fig. 8. Wear coefficient values for ball and plate specimens under critical load. * omitted value due to film failure.

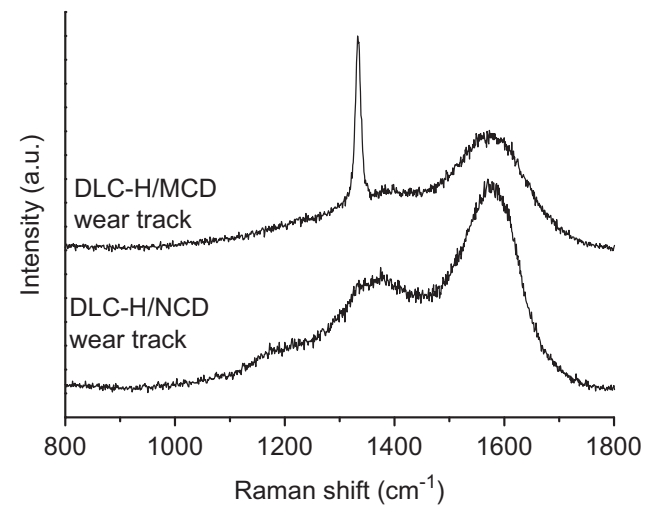

Fig. 9. UV micro-Raman spectra of worn DLC-H/diamond double layers.

$\sigma_{z z}=-p_{0}\left(1+z^{2} / a^{2}\right)^{-1}$

$\tau_{1}=0.5\left|\sigma_{z z}-\sigma_{x x}\right|$

where $W$ is the normal applied force, $R$ is the radius of the spherical indenter, $a$ is the contact radius, $p_{0}$ is the maximum pressure, $\sigma_{x x}$ and $\sigma_{z z}$ are the normal stresses in the $x$ and $z$ directions, and $E^{*}$ is the composite modulus of the two surfaces given as $1 / E *=\left(1-v_{1}^{2}\right) / E_{1}+\left(1-v_{2}^{2}\right) / E_{2}$ where $E_{i}$ are the elastic moduli and $v_{i}$ are Poisson's ratios of the two contacting surfaces [19]. Literature values of the elastic constants were considered to be a realistic approximation: $E=1143 \mathrm{GPa}$ and $v=0.07$ for microcrystalline diamond [20], and $E=87 \mathrm{GPa}$ and $v=0.22$ for hydrogenated DLC coatings [21].

To calculate the curves shown in Fig. 10 homologous contacts (MCD/MCD and DLC/DLC) and an applied load of $W=20 \mathrm{~N}$ were

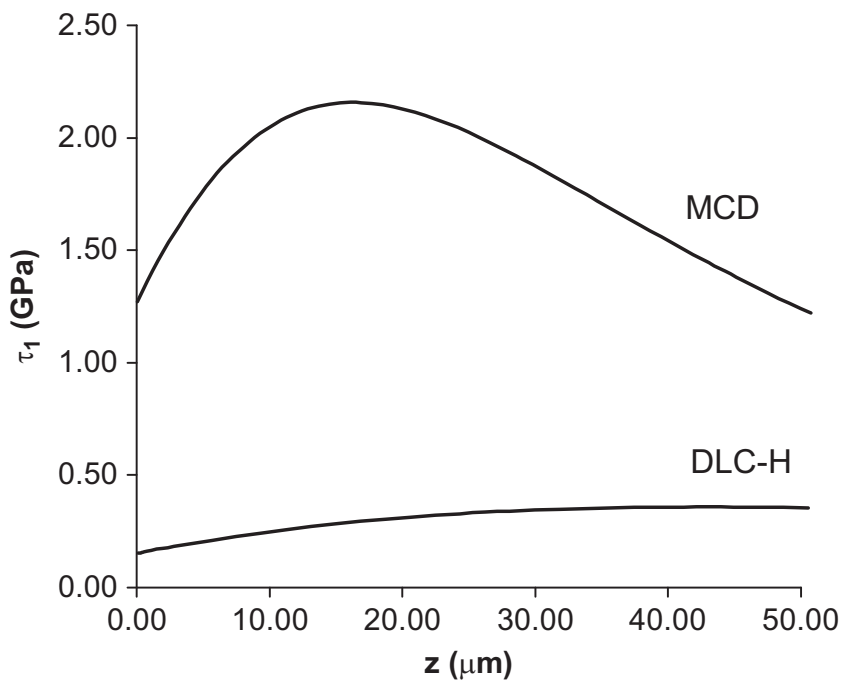

Fig. 10. Maximum shear stress evolution beneath the normal contact of a spherical indenter and a flat surface, both coated with MCD or DLC, for an applied load of $20 \mathrm{~N}$.

used, as an example to illustrate the differences between these materials regarding the shear stress along the $z$-axis. It can be seen that DLC presents much lower maximum shear stress values than MCD, revealing a high potential to provide good lubricity when deposited on diamond coatings. This was proved in the present work, with the decrease of the coefficient of friction of MCD coatings during the first instants of sliding by the deposition of DLC thin films (Fig. 6).

The other significant result obtained is the increase of the critical load from $20 \mathrm{~N}$, for homologous contacts of MCD, to $60 \mathrm{~N}$, for homologous contacts of DLC-H/MCD (Fig. 5). Such improvement on the bearing capacity of the coatings is related to the net change of the stress field beneath the spherical contact provoked by friction, relatively to the static Hertzian contact [9]. In normal contact $(\mu=0)$, the maximum shear stress occurs below the surface, as it can be seen in Fig.10. According to Hamilton [9], friction moves this original maximum closer to the surface and, most important of all, a new region of likely failure develops in the surface at the back edge of contact $(x=-a)$. Beyond $\mu=0.25$ this new region dominates the stress field, i.e. the point of failure is located at the surface. As it is a three-dimensional stress field, the von Mises yield parameter, $\sqrt{J_{2}}$, is used to describe it. The values of the maximum yield parameter are given by [9]:

$\frac{\sqrt{J_{2}}}{p_{0}}=\frac{1}{\sqrt{3}}\left\{\frac{(1-2 v)^{2}}{3}+\frac{(1-2 v)(2-v) \mu \pi}{4}+\frac{\left(16-4 v+7 v^{2}\right) \mu^{2} \pi^{2}}{64}\right\}^{1 / 2}$ 


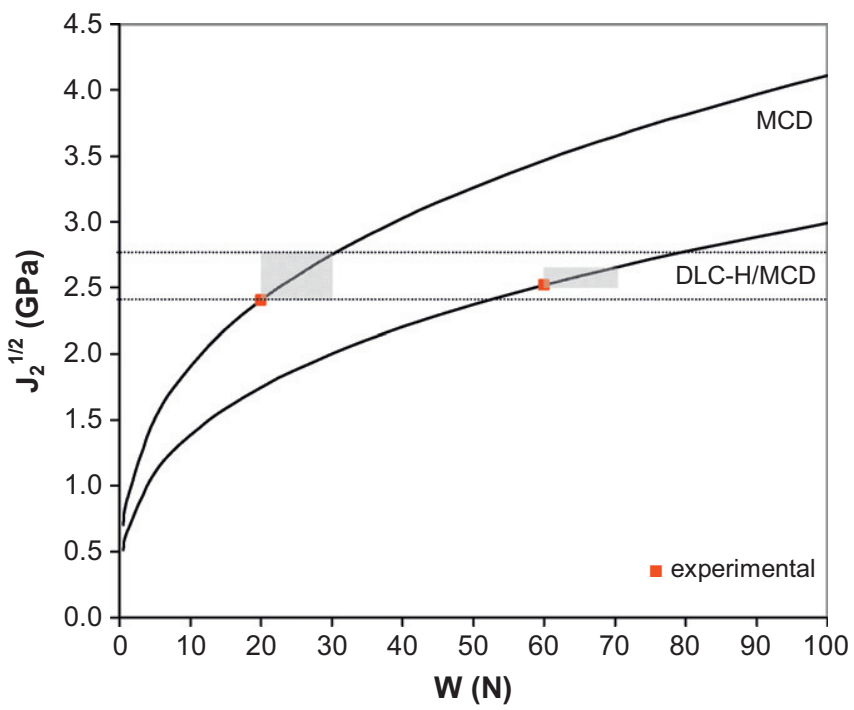

Fig. 11. Maximum von Mises yield parameter as a function of applied load for homologous sliding contact of MCD and DLC-H/MCD coated balls and plates. (For interpretation of the references to color in this figure caption, the reader is referred to the web version of this article.)

This equation was used to plot $\sqrt{J_{2}}$ as a function of normal load (Fig. 11) for the MCD monolayer and the DLC-H/MCD double layer homologous tests. In these, the initial coefficient of friction is always higher than 0.25 (Fig. 6) and the failure of the coating is likely to start at the surface induced by a critical load value. The coefficient of friction used in the calculations is the average value assessed during the tribological tests for each coating, since friction showed to be almost independent of applied load (standard deviation was only 0.06 ). Here, in the calculation of $p_{0}$, due to the very small thickness of the MCD and DLC-H/MCD coatings, and for a more realistic approach, the elastic deformation was calculated using only the contribution of the ceramic substrates, while for the $X Y$ surface deformation Poisson's ratio used is that of the diamond.

In Fig. 11, the little red square marks indicate the test load, immediately below the one where failure occurred or, as it has been named, the critical load. However, the tests were performed with intervals of $10 \mathrm{~N}$, so there is a window of load values, the big gray square, that were not tested and that the coatings may still bear. The von Mises yield parameter has a range of possible values in that window, defining the stress range that the coatings may be able to withstand. From the analysis of the curves of Fig. 11, it can be concluded that the reduction of the $\mu$ value for the DLC-H/MCD double layer results in an increase of the critical load when submitted to the same stress state $\sqrt{J_{2}}$ of MCD. The experimental value obtained for the critical load of DLC-H/MCD $(60 \mathrm{~N})$ is within the interval of predicted values $(52-80 \mathrm{~N})$ determined from the range of maximum yield parameter values of MCD (limited by the horizontal dotted lines in Fig. 11).

The graph of Fig. 11 is very clear in showing the importance of reducing the friction coefficient to improve the load bearing capacity of the coatings. The approach hereby discussed can be applied to other combinations of films and contribute to the design of low-friction and high-bearing capacity systems for highdemanding tribological applications.

\section{Conclusions}

DLC/diamond bilayers were successfully produced by growing thin (350-540 nm of thickness) DLC lubricant coatings, using DC magnetron sputtering, on the top of CVD diamond films produced by HFCVD (thickness range: 3-6 $\mu \mathrm{m}$ ). Two grain-size diamond varieties, microcrystalline (MCD) and nanocrystalline diamond (NCD), were combined with two types of DLC films, non-hydrogenated and hydrogenated ones (DLC-H). No significant morphological differences were induced on the diamond surfaces by the deposition of the DLC outer layer. However, UV-Raman spectroscopy revealed a typical amorphous carbon spectrum instead of the diamond signature.

Unlubricated self-mated tests assessed the tribological behaviour of the coatings. Samples coated with MCD present higher initial friction peaks than the ones with NCD due to the higher nominal surface roughness. The deposition of DLC films allowed the reduction of friction values in the first instants of sliding, mainly in the MCD case. The DLC outer layers perform a sacrificial role in such initial moments as they rapidly worn-out. Notably, a significant increasing of the critical load for film failure, from $20 \mathrm{~N}$ to $60 \mathrm{~N}$, takes place due to the decrease of the initial friction peak, from 0.76 to 0.41 , when a DLC-H/MCD double layer is used. While the elastic properties of DLC-H accounts for a reduction of the shear stress in a static hertzian contact, the application of the von Mises maximum yield parameter criterion to sliding contacts demonstrates to be an adequate method to describe the dependence of the bearing capacity on the initial friction coefficient value.

\section{Acknowledgments}

This work was conducted under the framework of FCT project MULTIDIACOAT-PTDC/EME-TME/100689/2008. M. Amaral acknowledges FCT for the grant SFRH/BPD/26787/2006.

\section{References}

[1] C.S. Abreu, F.J. Oliveira, M. Belmonte, A.J.S. Fernandes, R.F. Silva, J.R. Gomes, Wear 259 (2005) 771-778.

[2] C.S. Abreu, F.J. Oliveira, M. Belmonte, A.J.S. Fernandes, J.R. Gomes, R.F. Silva, Tribology Letters 21 (2006) 141-151.

[3] J. Robertson, Materials Science and Engineering: R 37 (2002) 129-281.

[4] C. Donnet, A. Erdemir, Tribology Letters 17 (2004) 389-397.

[5] H. Hanyu, S. Kamiya, Y. Murakami, Y. Kondoh, Surface and Coatings Technology 200 (2005) 1137-1141.

[6] H.K. Csorbai, G. Kovách, G. Peto, P. Csíkvári, A. Karacs, A. Sólyom, Gy. Hárs, E. Kálmán, Applied Surface Science 253 (2007) 5070-5075.

[7] K. Miyoshi, Surface Engineering: Science and Technology I (1999) 307-317.

[8] K. Miyoshi, Tribology Letters 3 (1997) 141-145.

[9] G.M. Hamilton, Proceedings of the Institution of Mechanical Engineers $197 \mathrm{C}$ (1983) 53-59.

[10] M. Amaral, F. Almeida, A.J.S. Fernandes, F.M. Costa, F.J. Oliveira, R.F. Silva Surface and Coatings Technology 204 (2010) 3585-3591.

[11] M. Amaral, C.S. Abreu, F.J. Oliveira, J.R. Gomes, R.F. Silva, Diamond and Related Materials 16 (2007) 790-795.

[12] M. Massi, H.S. Massiel, C. Otani, R.D. Mansano, P. Verdonck, Journal of Materials Science: Materials in Electronics 12 (2001) 343-346.

[13] A.C. Ferrari, J. Robertson, Physical Review B 64 (2001) 75414.

[14] C. Casiraghi, A.C. Ferrari, J. Robertson, Physical Review B 72 (2005) 085401.

[15] L. Pastewka, S. Moser, M. Moseler, Tribology Letters 39 (2010) 49-61.

[16] J.D. Schall, G. Gao, J.A. Harrison, Journal of Physical Chemistry C 114 (2010) 5321-5330.

[17] J. Goldsmith, E. Sutter, J.J. Moore, B. Mishra, M. Crowder, Surface and Coatings Technology 200 (2005) 2386-2390.

[18] J.G. Buijnsters, M. Camero, L. Vázquez, F. Agulló-Rueda, R. Gago, I. Jiménez C. Gómez-Aleixandre, J.M. Albella, Diamond and Related Materials 19 (2010) 1093-1102.

[19] V.L. Popov, in: English (Ed.), Contact Mechanics and Friction: Physical Principles and Applications, Springer-Verlag, Berlin, Heidelberg, 2010.

[20] V.G. Ralchenko, A.A. Smolin, V.G. Pereverzev, E.D. Obraztsova K.G. Korotoushenko, V.I. Konov, YuV Lakhotkin, E.N. Loubnin, Diamond and Related Materials 4 (1995) 754-758.

[21] S.-J. Cho, K.-R. Lee, K.Y. Eun, J.H. Hahn, D.-H. Ko, Thin Solid Films 341 (1999) 207-210. 